\title{
Representational difference analysis of cDNA identifies novel genes expressed following preconditioning of the heart
}

\author{
M. A. C. Fauchon ${ }^{1}$, T. J. Pell ${ }^{2}$, G. F. Baxter ${ }^{3}$, \\ D. M. Yellon ${ }^{2}$, D. S. Latchman ${ }^{4}$ \\ M. F. Hubank ${ }^{4}$ and L. V. Mayne $e^{1,5}$ \\ ${ }^{1}$ Trafford Centre for Graduate Medical Education and Research \\ University of Sussex, Falmer, Brighton BN1 9RY, UK \\ ${ }^{2}$ The Hatter Institute for Cardiovascular Studies \\ Centre for Cardiology \\ University College London Hospital and Medical School \\ Grafton Way, London WC1E 6DB, UK \\ ${ }^{3}$ Department of Basic Sciences \\ The Royal Veterinary College, University of London \\ Royal College Street, London NW1 OTU, UK \\ ${ }^{4}$ Institute of Child Health \\ University College, London \\ 30 Guilford Street, London WC1N 1EH, UK \\ ${ }^{5}$ Corresponding author: Tel, 44(0)1273.678446; \\ Fax, 44(0)1273.872941; E-mail, I.mayne@sussex.ac.uk
}

Accepted 7 July 2005

Abbreviations: cDNA. RDA, representational difference analysis of CDNA; MAP kinase, mitogen-activated protein kinase; PC, preconditioning; RPA, ribonuclease protection assay

\footnotetext{
Abstract

Preconditioning of the myocardium rapidly induces a number of transcription factors, which are likely to be responsible for a cascade of transcriptional changes underlying the development of delayed adaptation. Identifying these changes provides in sight into the molecular pathways elicited by sub-lethal ischaemia and the mechanism leading to delayed adaptation. Genes up-regulated in rabbit myocardium in vivo by ischaemic preconditioning following reperfusion for $2 \mathrm{~h}, 4 \mathrm{~h}$ and $6 \mathrm{~h}$ posttreatment were identified by representational difference analysis of cDNA (cDNA. RDA). The area of the left ventricle rendered ischaemic by preconditioning or the equivalent area of sham-treated animals was isolated and cDNA.RDA performed. Three novel genes and six genes with known function where identified, including the TGF $\beta$ receptor interacting protein 1, the $\alpha$ isoform of the $A$ subunit of PP2 and the cap binding protein NCBP1. To determine whether expression of these genes
}

correlated with preconditioning per se, expression was measured in myocardium after both ischaemic as well as heat shock induced preconditioning following $2 \mathrm{~h}, 4 \mathrm{~h}$, and $6 \mathrm{~h}$ reperfusion. These genes were induced in rabbit myocardium in vivo by both ischaemia and heat shock, consistent with a fundamental role in the development of delayed adaptation. The well described role of PP2 in modulating the mitogen-activated protein kinase pathway and promoting cell survival is consistent with our previous work, which identified the reperfusion injury salvage kinase pathway in mediating the protective effects of ischaemic preconditioning. Expression of Trip1 and Ncbp1 also implicates TGF $\beta$ signalling pathways and RNA processing and transport in delayed adaptation to stress in the myocardium.

Keywords: gene expression profiling; heat-shock response; ischemic preconditioning, myocardial; myocardial ischemia; myocardium; reperfusion

\section{Introduction}

In the myocardium, short periods of sublethal ischaemia induce tolerance to subsequent periods of acute ischaemia. This preconditioning or adaptation of the myocardium is manifested at two different times (Kuzuya et al., 1993; Marber et al., 1993). The first period of protection appears rapidly after the preconditioning treatment, but is short-lived disappearing within 1-2 h (Murry et al., 1986). In contrast, the second period appears later around $24 \mathrm{~h}$ after preconditioning (Marber et al., 1993; Kuzuya et al., 1993) and lasts for an extended time (48-72 h; Baxter et al., 1997). As this late period of protection extends over several days and protects against a variety of ischaemic pathologies, including irreversible cell and tissue injury, myocardial stunning, vascular endothelial dysfunction and ventricular arrhythmia (Baxter and YelIon, 1998), it may offer an important target for pharmacological intervention.

The molecular basis of delayed adaptation to ischaemia is poorly understood. The rapid induction of a variety of transcription factors in response to ischaemia suggests that transcriptional changes may play an important role in the adaptive processes manifested at later times (Mayne, 1998). The immediate early genes, $c$-fos and members of the jun family 
(c-jun, jun-b and jun D), which together form the AP1 family of transcription factors, are rapidly induced by ischaemia and regulate a wide variety of downstream target genes. The rapid induction of the transcription factors EAT and Egr-1 is also seen (Brand et al., 1992; Matsushita et al., 1999). Both these transcription factors play a role in regulating cell death by apoptosis. As ischaemia can lead to apoptosis in the myocardium, adaptation to ischaemia may involve changes in regulation of these and other genes involved in apoptosis. Thus, studying changes in gene expression that precede adaptation will provide insight into the underlying molecular events.

In this paper, we examine changes in gene expression occurring in vivo in a rabbit model of ischaemic preconditioning. As many stress-response and survival genes are transcriptionally controlled, methods which identify transcriptional changes allow us to visualise the biochemical pathways activated in response to preconditioning stimuli. As Genechips and DNA microarrays were not available for the rabbit genome, we used representational difference analysis of cDNA (cDNA.RDA) (Hubank and Schatz, 1994, Hubank and Schatz, 1999) to identify upregulated genes. This method is a cDNA specific modification of the PCR-based subtractive hybridisation technique of representational difference analysis first described for application to whole genomes by (Lisitsyn and Wigler, 1993). cDNA.RDA is a versatile and powerful method for identifying differentially expressed genes and for identifying molecular processes in a variety of contexts (Hubank and Schatz, 1999). cDNA.RDA provides a unique window on changes in gene transcription, but does not survey the entire genome. The subset of genes identified will depend on the DNA sequence of the genes, their relative abundance and the physical parameters of the subtraction method.

Rabbit myocardium was preconditioned or sham treated and up-regulated genes identified following 2 $\mathrm{h}, 4 \mathrm{~h}$ and $6 \mathrm{~h}$ reperfusion. cDNA.RDA analysis identified six genes with known function and three novel genes up-regulated in response to ischaemic PC. Identification of five of these genes in the context of preconditioning is novel. For at least three of these genes (PPP2r1a, a subunit of the phosphatase PP2, the TGF $\beta$ interacting protein (Trip1) and Ncbp1), induction was conserved following heat shock induced preconditioning, consistent with these genes operating in pathways fundamental to the heart's ability to adapt to stress.

Transcriptional regulation of $P p p 2 r 1$ a predicts a role for PP2 in mediating preconditioning. The role of PP2 in modulating the mitogen-activated protein (MAP) kinase pathways is consistent with our previous work demonstrating the importance of the reperfusion injury salvage kinase pathway in mediating the protective effects of ischaemic preconditioning. PP2 may also play a role in the cross-talk between different signalling cascades activated in response to sub-lethal ischaemia and reperfusion. The up-regulation of Trip1 implicates the TGF $\beta$ signalling pathways and up-regulation of Ncbp1 implicates RNA processing and transport in delayed adaptation to stress in the myocardium. Our study using rabbit myocardium complements other gene expression studies following a variety of ischaemia/reperfusion protocols in rat (Onody et al., 2003; Simkhovich et al., 2003) and dog (Zubakov et al., 2003). As well as differences in treatment protocols, our study follows a time course of expression after preconditioning and extends the results from ischaemic preconditioning to heat shock induced preconditioning, providing evidence for a fundamental role of these genes independent of the preconditioning stimuli.

\section{Materials and Methods}

\section{Animals}

Male New Zealand White rabbits, weighing between 2.3 and $2.8 \mathrm{~kg}$ were acclimatised for approximately 7 days after delivery with free access at all times to a standard pelleted diet. Their care and use were in accordance with the UK Home Office Guidelines of the Animals (Scientific Procedures) Act 1986.

\section{Ischaemic preconditioning protocol}

Sixteen rabbits were randomly allocated to preconditioned or sham treated groups (eight per group, two animals per time point for each treatment). In brief, rabbits were premedicated with "Hypnorm" $0.1 \mathrm{ml} / \mathrm{kg}$ i.m. and surgical anaesthesia was induced with pentobarbitone sodium $30-50 \mathrm{mg} / \mathrm{kg}$. Positive pressure ventilation with a mixture of room air and oxygen was adjusted as necessary to maintain arterial $\mathrm{pH}$ in the range 7.35-7.50. Following mid-line sternotomy, a prominent anterior branch of the left coronary artery was under-run with a $3 / 0$ silk suture, the ends of which were threaded through a $15 \mathrm{~mm}$ polypropylene tube to form a snare. After administration of heparin sodium $300 \mathrm{IU} \mathrm{kg}$, regional myocardial ischaemia was induced by clamping the snare with a hemostat forceps. Reperfusion was instituted by releasing the snare. The preconditioning protocol consisted of four $5 \mathrm{~min}$ occlusions, each followed by $10 \mathrm{~min}$ of reperfusion. Control rabbits underwent identical procedures, without occlusion of the artery. Body temperature was monitored during treatment and maintained at $38 \pm 0.5^{\circ} \mathrm{C}$ by placing the animals on an electric heating mat. 
Following the preconditioning protocol, the myocardium was reperfused for $2 \mathrm{~h}, 4 \mathrm{~h}, 6 \mathrm{~h}$ or $24 \mathrm{~h}$. Animals reperfused for $2 \mathrm{~h}, 4 \mathrm{~h}$ and $6 \mathrm{~h}$ remained under anaesthetic. Animals reperfused for $24 \mathrm{~h}$ underwent sterile surgery and were allowed to recover from anaesthesia with the use of analgesics. $24 \mathrm{~h}$ later animals were re-anaesthetised and surgically prepared as for preconditioning.

Following reperfusion, animals were sacrificed and the heart was removed within one minute of death. The heart was thoroughly rinsed in ice cold sterile PBS to remove free blood and the area of the left ventricle rendered ischaemic by preconditioning was removed by dissection. The tissue was placed in RNAzol (Biotecx Laboratories) and coarsely chopped.

\section{Heat treatment}

Pentobarbitone anaesthetised animals $(n=4)$ were wrapped in an electric blanket and heated for 15 minutes until the rectal temperature reached $42 \pm$ $0.2^{\circ} \mathrm{C}$. Control animals $(n=4)$ were anaesthetised and kept at room temperature for $15 \mathrm{~min}$. Animals were left to recover for $2 \mathrm{~h}, 4 \mathrm{~h}$ or $6 \mathrm{~h}(2$ animals per time point) and were then re-anaesthetised and sacrificed. The heart was rapidly removed and rinsed thoroughly in ice cold PBS. The whole left ventricle was excised, placed in RNAzol (Biotecx Laboratories) and coarsely chopped.

\section{RNA extraction and purification}

Cardiac tissue was homogenised in RNAzol $(20 \mathrm{ml} / \mathrm{g}$ of tissue) using a Polytron Kinematica homogeniser. Total RNA was purified by phenol extraction and isopropanol precipitation. The quality and yield was monitored by gel electrophoresis and optical density under UV light.

\section{CDNA.RDA}

cDNA.RDA was performed essentially as previously described (Hubank and Schatz, 1994; 1999) using cardiac tissue isolated from control and preconditioned animals reperfused for $2 \mathrm{~h}, 4 \mathrm{~h}$ and $6 \mathrm{~h}$. Poly-A+ mRNA was isolated from cardiac total RNA and used to synthesize cDNA by standard methods. Representations for control and preconditioned animals were generated in 20 identical PCR reactions following 20 amplification cycles. Identical PCR products were pooled. Three successive cycles of subtraction hybridisation and amplification were performed using each paired set of control and PC representations. The ratio of PC:control DNA in each cycle were: DP1 (1:100), DP2 (1:800) and DP3 1:400,000 (for the $2 \mathrm{~h}$ time point and 1:40,000 for the $4 \mathrm{~h}$ and 6 $\mathrm{h}$ time point). The J-adapters were removed from the
DP3 DNA by digestion with DPNII. Purified DP3 DNA was cloned into the vector pBluescript II KS (+/-) (Stratagene). Vector inserts ranged in size from 270-430 bp.

\section{DNA sequence analysis}

Isolated DNA fragments were automatically sequenced (ABI 3310, School of Biological Sciences, University of Sussex) and homologies to known DNA sequences were determined by NCBI Blast analysis.

\section{Ribonuclease protection assay (RPA)}

DP3 sequences cloned into pBluescript II KS (+/-) were linearised downstream of the insert. Antisense RNA was generated using a Maxiscript in vitro transcription kit (Ambion) and either $\mathrm{T}_{3}$ or $\mathrm{T}_{7}$ polymerase following the manufacturer's instructions. For Trip1, Ncbp1, and Ppp2r1a, $62.5 \mathrm{pmol}\left[\alpha^{32} \mathrm{P}\right]$ UTP (800 $\mathrm{Ci} / \mathrm{mmol}, 10 \mathrm{~m} \mathrm{Ci} / \mathrm{ml}$ - ICN) were included in the reaction. For the $18 \mathrm{~S}$ ribosomal RNA (rRNA) control, reactions contained $62.5 \mathrm{pmol}\left[\alpha-{ }^{32} \mathrm{P}\right]$ UTP and 6 nmol unlabelled UTP. The DNA template was removed by treating the sample with $2 \cup$ DNase I for 15 min at $37^{\circ} \mathrm{C}$ and the RNA probe was gel purified. The specific activity of the Trip1, Ncbp1, and Ppp2r1a probes were routinely $10^{9} \mathrm{cpm} / \mu \mathrm{g}$, whereas the specific activity of the $18 \mathrm{~S}$ rRNA probe was $10^{7} \mathrm{cpm} / \mu \mathrm{g}$.

The RPA was performed using the HybSpeed RPA kit from Ambion according to the manufacturer's instructions. In all reactions, the probe was in molar excess over the target fragment in the hybridisation reaction. The radiolabelled probe annealed to the RNA sample was resolved on a $5 \%$ native acrylamide gel for $3 \mathrm{~h}$ at $100 \mathrm{~V}$. Control samples (probe alone and digested probe) were heated for $3 \mathrm{~min}$ at $95^{\circ} \mathrm{C}$ and were electrophoresed on a denaturing $5 \%$ acrylamide gel with $8 \mathrm{M}$ urea for $3 \mathrm{~h}$ at $100 \mathrm{~V}$. Gels were transferred to Whatmann $3 \mathrm{MM}$ paper, dried for 20 min at $80^{\circ} \mathrm{C}$ on a vacuum gel drying and exposed to X-ray film (Kodak).

All RPA autoradiograms were quantified by computerised gel scanning and densiometric analysis (ImageMaster Software, Version 1.10 Pharmacia Biotech). Results were normalised relative to the signal obtained for the internal control $18 \mathrm{~S}$ ribosomal RNA. The mRNA level of each transcript was expressed as a percentage of its corresponding control level (untreated sample) at the appropriate experimental time point. Assays were run in duplicate and results expressed as means.

\section{Cloning the full length Trip1 cDNA}

Rapid amplification of cDNA ends (RACE PCR) used the Marathon-Ready cDNA amplification kit (Clontech 
Laboratories) according to the manufacturer's instructions. Trip1 specific primers were synthesised on an Applied Biosystems 381A DNA synthesizer (University of Sussex). The DNA sequence was deposited in GenBank (accession no. AY727926).

\section{Results}

\section{Ischaemic preconditioning}

The rabbit myocardium was preconditioned by occluding the artery four times for a period of five minutes, with a ten minute period of reperfusion between occlusions. Sham treated animals underwent identical procedures without occluding the artery. Two animals were used for each time point. Following the preconditioning protocol or sham treatments, animals were reperfused for various times $(2 \mathrm{~h}, 4 \mathrm{~h}, 6 \mathrm{~h}$ or 24 h) before being sacrificed. Preconditioned animals were designated ot $(2 \mathrm{~h}), \beta \mathrm{t}(4 \mathrm{~h}), \gamma \mathrm{t}(6 \mathrm{~h})$, and $\delta \mathrm{t}(24$ h) and sham treated animals were designated Ac (2 h), Bc (4 h), Cc (6 h) and Dc (24 h).

\section{Representational difference analysis}

cDNA was prepared from the area of the left ventricle rendered ischaemic by preconditioning or shamtreated. 'Representations' were generated for each sham-treated and preconditioned pair of animals and are shown in Figure 1A. DNA sequences enriched in each preconditioned population relative to the shamtreated population were identified following three cycles of subtractive hybdridisation and amplification. The difference products isolated after each cycle (DP1, DP2 and DP3) are shown in Figure 1B. The DP3 products were excised from each gel as three broad bands covering the region $300-500 \mathrm{~kb}$ and the DNA was purified and cloned. Approximately 25 clones were analysed for each DP3 product. Clones were designated $\alpha$, $\beta$, or $\gamma$ (representing $2 \mathrm{~h}, 4 \mathrm{~h}$ and $6 \mathrm{~h}$ respectively) as appropriate. To identify unique DNA sequences, inserts were isolated from each clone and cross-hybridised to each other on Southern blots (data not shown). 35 unique DNA sequences were identified (14 $\alpha$ clones, $14 \beta$ clones, and 7 $\gamma$ clones).

Southern analysis was used to confirm up-regulation of the identified sequences in the representations from preconditioned tissue and enrichment during subtractive hybridisation and amplification, data are shown in Figure 2. From the 35 unique sequences, up-regulation during PC was confirmed for 11 sequences. For the majority of sequences, band size was identical in the treated and control representations as expected. However, four sequences (alpha $1 \mathrm{c}$, alpha $2 \mathrm{~b}$, alpha $2 \mathrm{~d}$ and gamma $2 \mathrm{~b}$ ) showed different sized bands in the control and treated representations. This may represent changes in cDNA structure possibly due to alternative mRNA splicing.

To establish the identity of the up-regulated genes, the eleven DNAs were sequenced and compared with known sequence databases. Table 1 lists the clone designation, homology to previously described genes and the gene (protein) function. For three of the
A

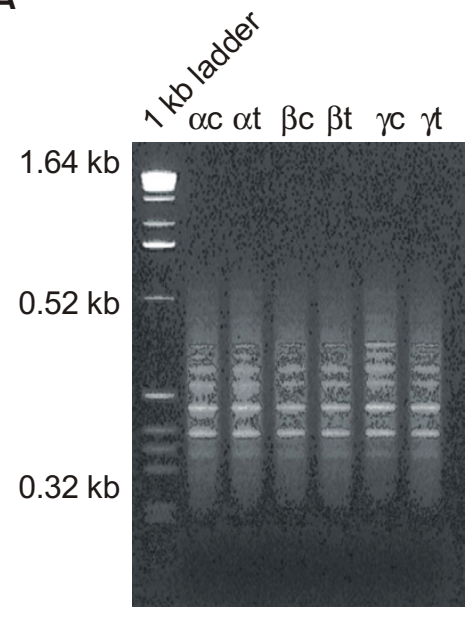

Representations

B

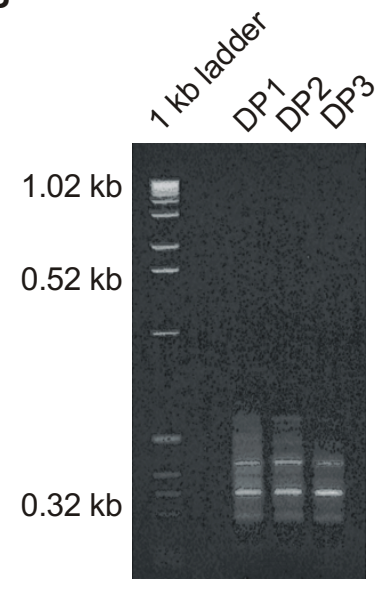

$2 \mathrm{~h}$

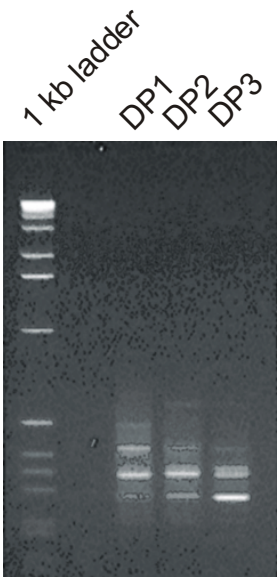

$4 \mathrm{~h}$

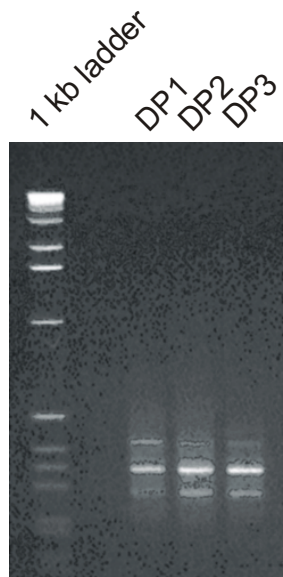

$6 \mathrm{~h}$

Figure 1. Representations and difference products. (A) Representations were generated from each cDNA population. Representations for control (c) and treated samples (t) were run on agarose gels. $\alpha \mathrm{c} 2 \mathrm{~h}$ control representation; $\alpha \mathrm{t} 2 \mathrm{~h}$ treated; $\beta \mathrm{c} 4 \mathrm{~h}$ control; $\beta \mathrm{t} 4 \mathrm{~h}$ treated, $\gamma \mathrm{c} 6 \mathrm{~h}$ control, $\gamma \mathrm{t} 6 \mathrm{~h}$ treated. (B) Difference products, DP1, DP2 and DP3 were generated using the representations from the $2 \mathrm{~h}, 4 \mathrm{~h}$ and $6 \mathrm{~h}$ cDNAs shown in panel A. Left to right: DP1, DP2 and DP3 isolated from the $2 \mathrm{~h}, 4 \mathrm{~h}$ representations, respectively. Size marker: $1 \mathrm{~kb}$ ladder, sizes are indicated to the left. 


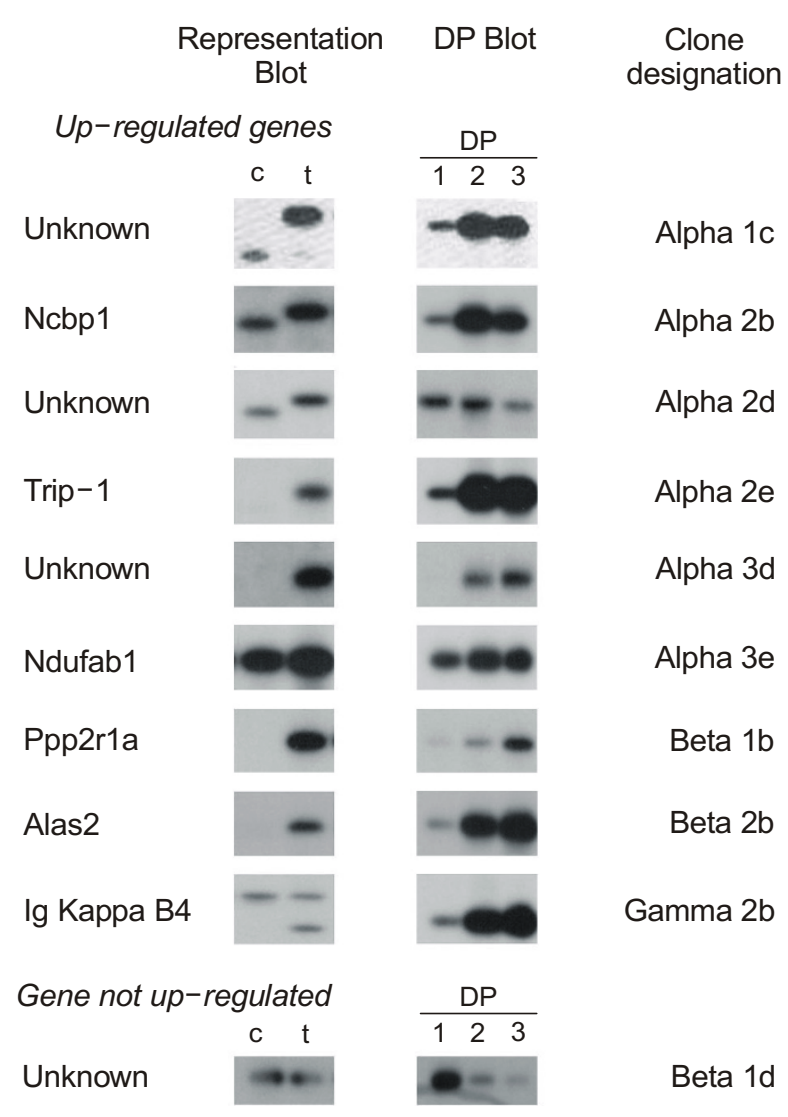

Figure 2. Southern blot analysis of representations and difference products. Inserts from each DNA clone isolated following the cDNA.RDA analysis were hybridised to a Southern blot of the control and treated representations and to a Southern blot of the DP1, DP2 and DP3 products. The first column shows the Southern blot from the control (c) and treated $(\mathrm{t})$ representations. The second column shows the Southern blot of the difference products. The clone designation and gene identity are given in the third and fourth columns. For comparison, representation and DP blots are shown for a gene which is not up-regulated (beta 1d).

DNAs, there was no significant homology to sequences in the databases (NB the rabbit genome is not yet fully sequenced). The remaining eight sequences showed $>90 \%$ homology to rabbit or human genes.

Three of the DNA sequences appeared to originate from the nuclear encoded mitochondrial delta-aminolevulinate synthase 2 gene (Alas2), and together spanned approximately $50 \%$ of the gene sequence. Though Alas2 was previously shown to be regulated by ischaemia in rat heart (Simkhovich et al., 2003), it is unlikely that this erythrocyte specific Alas 2 gene is transcriptionally regulated in these experiments as mature erythrocytes are enucleate and cannot transcribe new RNAs. Alas2 mRNA stability and turnover are, however, tightly regulated and coupled to oxygen demands (May et al., 1990). The ischaemic conditions in these experiments may alter Alas2 mRNA stability or may increase the presence of erythrocytes in the myocardium.

Ndufab1 is a nuclear encoded gene for the acyl carrier protein of mitochondrial NADH dehydrogenase, part of the mitochondrial complex I (Cl; Runswick et al., 1991). NADH dehydrogenase mRNA was shown previously to be decreased following oxidative stress (Carper et al., 1999). Impairment of Cl function enhances production of reactive oxygen species (Barrientos and Moraes, 1999) and can lead to apoptosis. These results suggest that increased synthesis of $\mathrm{NADH}$ dehydrogenase mRNA during PC may compensate for inhibition of mRNA synthesis induced by acute ischaemia, thus providing protection against apoptosis resulting from mitochondrial dysfunction.

IGKappaB4 is a B-cell expressed gene for the immunoglobulin light chain (kappa), which was highly expressed at $6 \mathrm{~h}$ with only low levels detectable at earlier time points (data not shown). While it is unlikely that PC is inducing an antibody:antigen response, we interpret these results as suggesting that PC may induce lymphocyte infiltration into the myocardium. This may offer a protective effect if further acute ischaemia is experienced and may help to suppress detrimental effects of the immune/inflammatory response to acute ischaemic damage.

Induction of Ncbp1, Trip1 and Ppp2r1a gene expression in the context of ischaemia and preconditioning has not previously been reported and we therefore undertook a detailed analysis of their expression to explore their potential role in PC. A second series of animals were $P C$ or sham treated and the time course was extended to $24 \mathrm{~h}$. RNA protection assays were used to quantitate levels of gene expression using both the original and second series of animals. To control for variation in the total amount of RNA in individual assays, 18S RNA was used as an internal control. Parallel experiments were performed (data not shown) to confirm that the amount of $18 \mathrm{~S}$ RNA did not vary under the conditions of these experiments.

Data from the RPA analyses are shown in Figure 3. The top section in each panel shows a representative autoradiogram for each gene and the corresponding 18 S RNA control indicating the amount of total RNA in each assay tube. The autoradiograms were scanned and densitometric analysis performed to quantify the results. For each gene, levels of expression were adjusted to take account of the variable amounts of RNA in each assay tube and loading differences onto the gels. These data for the corresponding autoradiogram are shown in the lower section of each panel; gene expression in the preconditioned myocardium is expressed as a percentage of the level of expression in the parallel, sham 
Table 1. Identification of cloned sequences up-regulated following ischaemic PC.

\begin{tabular}{|c|c|c|c|c|c|}
\hline $\begin{array}{c}\text { Clone } \\
\text { designation }\end{array}$ & $\begin{array}{c}\text { Product } \\
\text { length }\end{array}$ & $\begin{array}{c}\% \\
\text { Homology }\end{array}$ & $\begin{array}{c}\text { Gene } \\
\text { designation }\end{array}$ & Gene name & Protein function \\
\hline$\alpha 1 c$ & $430 \mathrm{bp}$ & - & Unknown & & \\
\hline$\alpha 2 b$ & 341 bp & $91 \%$ & Ncbp1 & $\begin{array}{l}\text { Nuclear cap binding protein } \\
\text { subunit } 1,80 \mathrm{kd} \text { subunit } \\
\text { (human) }\end{array}$ & Pre-mRNA splicing \\
\hline$\alpha 2 d$ & 340 bp & - & Unknown & & \\
\hline$\alpha 2 \mathrm{e}$ & 347 bp & $91 \%$ & elF3s2 Trip1 & $\begin{array}{l}\text { Eukaryotic initiation factor } 3 \text {, } \\
\text { subunit } 2 \text { (beta } 36 \mathrm{kD} \text { ) (human) } \\
\text { Also known as TGF } \beta \text { interacting } \\
\text { protein } 1\end{array}$ & $\begin{array}{l}\text { Initiation of protein translation } \\
\text { TGF- } \beta \text { interacting protein }\end{array}$ \\
\hline$\alpha 3 d$ & $271 \mathrm{bp}$ & - & Unknown & & \\
\hline$\alpha 3 e$ & 280 bp & $91 \%$ & Ndufab1 & $\begin{array}{l}\text { Mitochondiral acyle carrier } \\
\text { protein (human) }\end{array}$ & $\begin{array}{l}\text { Respiration, part of } \mathrm{NADH} \\
\text { dehydrogenase }(\mathrm{C} 1) \text { complex }\end{array}$ \\
\hline$\beta 1 b$ & 398 bp & $93 \%$ & Ppp2r1a & $\begin{array}{l}\text { Protein Phosphatase A } \\
\text { regulatory subunit (PR65 } \alpha \text { ), } \\
\text { alpha isoform (human) }\end{array}$ & Serine-threonine phosphatase \\
\hline$\beta 2 c$ & 324 bp & $89 \%$ & Alas2 & Delta-aminolevulinate synthase & Rate limiting enzyme for heme \\
\hline$\beta 2 d$ & 359 bp & $90 \%$ & & 2 (human) & biosynthesis in mitochondria \\
\hline$\beta 3 a$ & 283 bp & $91 \%$ & & & \\
\hline$\gamma 2 b$ & 288 bp & $98 \%$ & IGKappaB4 & $\begin{array}{l}\text { Immunoglobulin Kappa chain } \\
\text { (allele bas) (rabbit) - locus no. } \\
\text { OCIG01 }\end{array}$ & Immunoglobulin \\
\hline
\end{tabular}
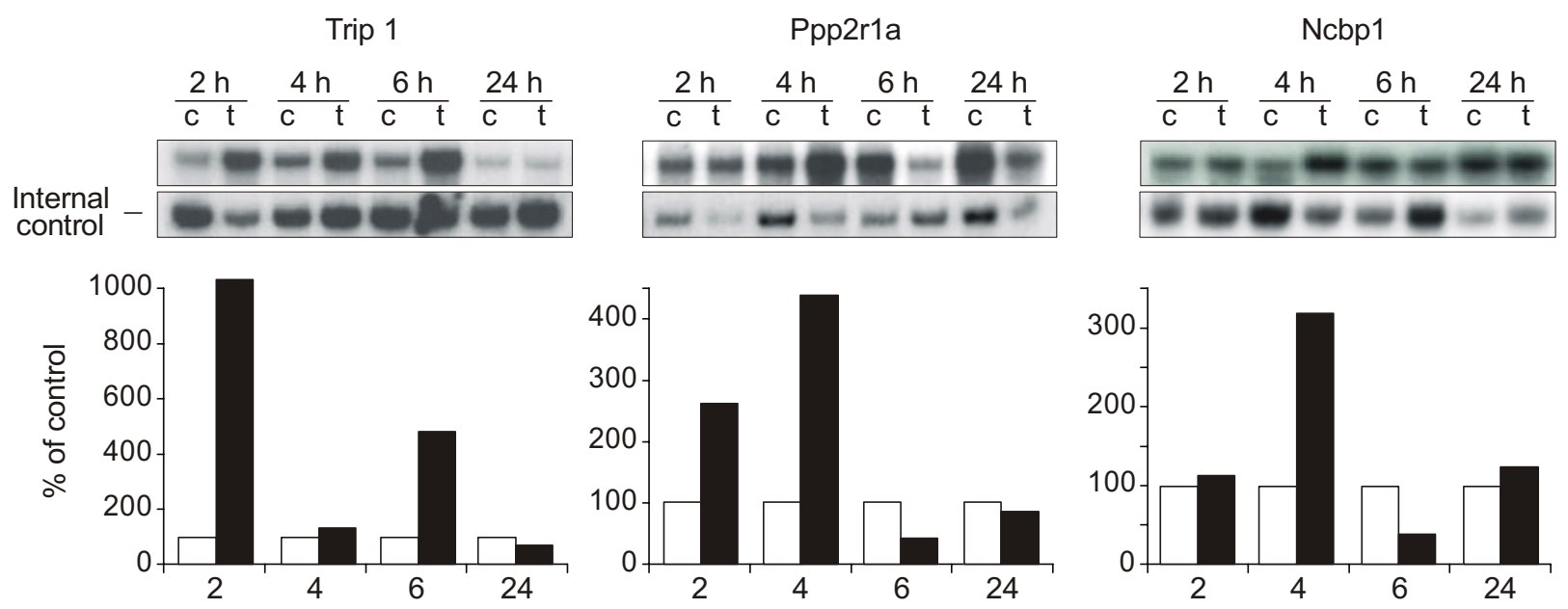

Time after ischaemic preconditioning (h)

Figure 3. RPA analysis of gene expression after ischaemic PC. mRNA levels for Trip1, Ppp2R1a and Ncbp1 were measured by RPA analysis at various different times after reperfusion. Representative autoradiograms are shown in the upper section of each panel. Autoradiograms were densitometrically scanned and the data plotted in the lower part of the panel. Estimates of total RNA were based on amounts of $18 \mathrm{~S}$ RNA in the same sample and were measured by RPA at the same time. In the lower section of each panel, the relative amount of each mRNA in PC (treated) and control (sham-treated) samples is shown over the time course. Estimates of mRNA were adjusted for different amounts of sample loaded in each well. Lane 1, $\alpha \mathrm{c}, 2 \mathrm{~h}$ control representation; lane 2, $\alpha \mathrm{t}, 2 \mathrm{~h}$ treated; $\beta \mathrm{c}, 4 \mathrm{~h}$ control; lane $4, \beta \mathrm{t}, 4 \mathrm{~h}$ treated; lane 5, $\gamma \mathrm{c}, 6 \mathrm{~h}$ control; $\gamma \mathrm{t}, 6 \mathrm{~h}$ treated. 


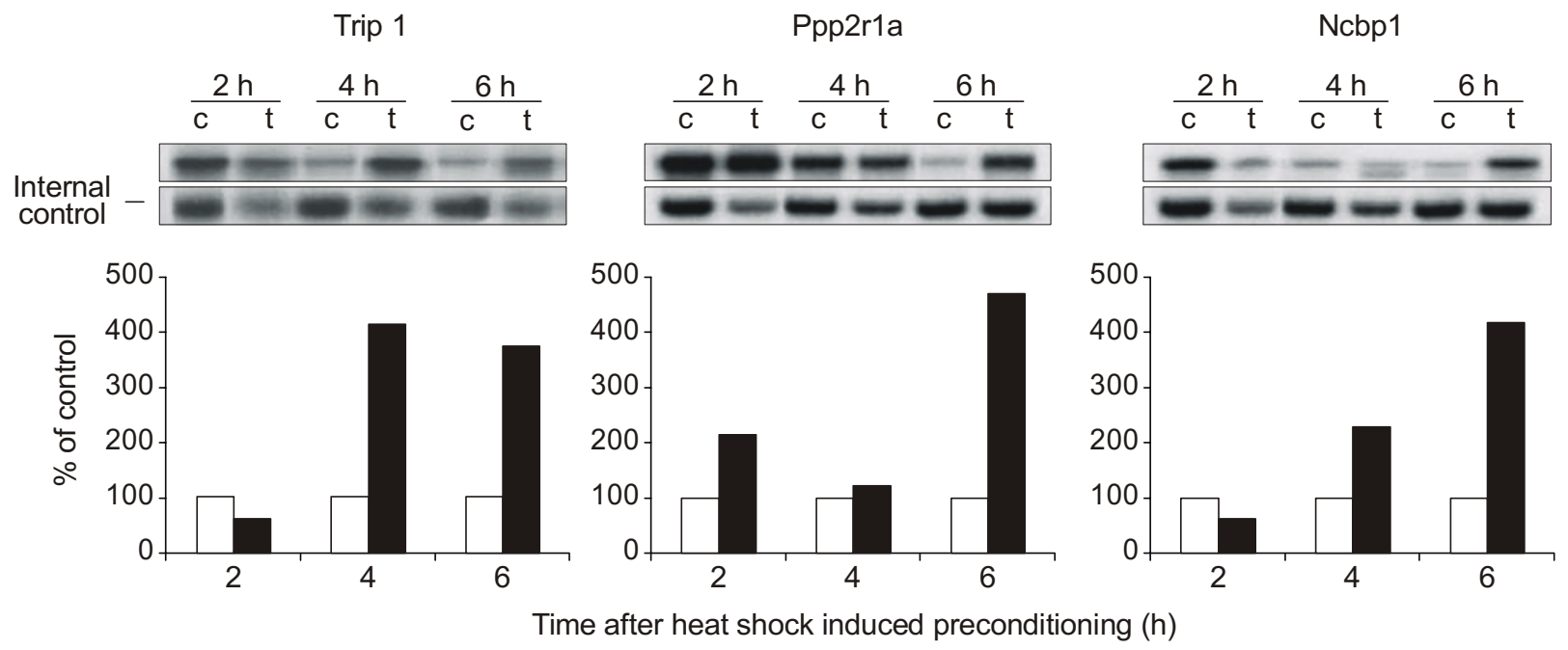

Figure 4. RPA analysis of gene expression after heat shock. mRNA levels were measured by RPA analysis for Trip1, Ppp2r1a and Ncbp1 after heat shock treatment at various times after treatment. Data presentation and analysis are essentially as described for Figure 3.

treated myocardium.

In the sham treated animals, the level of expression of the genes under study varied over the time course of these experiments (e.g. see Figure 3 and Figure 4, samples marked $\mathrm{C}$ ). Though the control animals were not preconditioned, they were anaesthetised and the chest cavity was surgically opened. Expression of these genes thus appears to be sensitive to surgical stress and/or treatment with anaesthetics. However, for the purpose of this study, we focused on the relative change in levels of gene expression between the PC and sham treated animals and for each treatment, data is presented as the percentage of PC to sham treated.

The RPA analysis of Trip1 expression (Figure 3) indicated rapid induction of Trip1 in preconditioned animals with maximum levels of expression at $2 \mathrm{~h}$. The level of induction seen in individual preconditioned animals varied between experiments. Though Trip1 was consistently up-regulated in all animals following preconditioning, the maximal level of induction varied between animals and ranged from 2.7 -fold to 10 -fold. This variability may reflect either individual differences in magnitude of the response or individual differences in the kinetics of the reaction e.g. peak levels may have been reached at $2 \mathrm{~h}$ for the animal where induction was 10 -fold, but before or after the $2 \mathrm{~h}$ time point in the case where induction was 2.7-fold. Ppp2r1a expression was induced 3.5 to 4-fold in these experiments with peak expression 4-6 $\mathrm{h}$ after preconditioning. Expression of Ncbp1 was elevated 2.7-3.2 fold and again peak expression was seen 4-6 $\mathrm{h}$ after preconditioning. In one series of animals, expression of both Ppp2r1a and Ncbp1 remained elevated at $24 \mathrm{~h}$. As for Trip1, variability in the time course between experiments may reflect variability in the individual responses of different animals or experimental variability in the preconditioning process. However, while the time course of induction varied in some experiments, all the genes analysed were consistently up-regulated in both independent series of preconditioned animals.

\section{Gene expression following heat shock induced PC}

The ability of the myocardium to adapt to potentially lethal damage was first recognised in response to heat shock and later shown to extend to ischaemia as well (Currie and Plumier, 1998). The mechanism underlying $P C$ to both heat shock and ischaemia is believed to be similar and similar changes in the expression of heat shock proteins are seen after both treatments (Currie and Plumier, 1998). We therefore investigated whether the transcriptional response of Trip1, Ppp2r1a and Ncbp1 was conserved in heat induced PC.

Rabbits were heat $\left(42^{\circ} \mathrm{C}\right.$ for $\left.15 \mathrm{~min}\right)$ or shamtreated, allowed to recover and sacrificed at $2 \mathrm{~h}, 4 \mathrm{~h}$ or $6 \mathrm{~h}$ after treatment. Hearts were excised and RNA isolated as described above. RPA analysis was performed to measure expression of Trip1, Ppp2r1a or Ncbp1 and the data are presented in Figure 4 . For all three genes, if we compare the level of expression in the sham-treated animals at $2 \mathrm{~h}$, we see high levels of expression, which diminish at later times. This suggests these genes are stress induced and that the sham-treatment itself induced gene expression. How- 
ever, in contrast to the heat treatment, control levels were low at $6 \mathrm{~h}$.

For all three genes, the heat induced preconditioning regime led to an approximate 4 to 5 -fold increase in gene expression over the levels in sham treated animals. Trip 1 and Ncbp1 were elevated at both 4 and $6 \mathrm{~h}$. Ppp2r1a appeared to be elevated only at $6 \mathrm{~h}$, however, expression levels were high in the heat treated animals at $4 \mathrm{~h}$ but the high levels in control at this time may obscure any heat effects. These data indicate that up-regulation of Trip1, Ppp2r1a and Ncbp1 is common to the mechanism of preconditioning and is independent of the PC stimulus.

\section{Validation of Trip1 identify}

Several studies indicated a role for the TGF $\beta$ signalling cascade in the development of cardioprotection during PC (Lefer et al., 1990, Roberts et al., 1993). As Trip1 interacts with the TGF $\beta$ receptor (Chen et al., 1995) with a potential role in modulating TGF $\beta$ signalling (Choy and Derynck, 1998) and the rabbit Trip1 cDNA was not previously described, we cloned and sequenced the full length rabbit cDNA to confirm its identity. Rabbit Trip1 encoded an open reading frame composed of 999 nucleotides encoding a predicted protein sequence of 333 amino acids (GenBank accession no. AY727926). The rabbit sequence was $92 \%$ homologous to the human TRIP1 sequence at the nucleotide level and 97\% homologous at the protein level (data not shown), consistent with the designation of this sequence as rabbit Trip1 (elF3s2).

\section{Discussion}

cDNA.RDA analysis is a powerful method for identifying differences in gene expression patterns. While subtraction methods of any type do not 'survey' all transcriptional changes that are occurring, each method provides a unique window on those changes. The subset of genes identified will in each case depend on the DNA sequence of the gene, its relative abundance and the physical parameters of the subtraction method, which will vary from method to method. The relative simplicity and power of the cDNA.RDA method allowed us to examine preconditioning in vivo in a well-described rabbit model of cardiac preconditioning at several time points after treatment. As transcription of most genes correlates with their protein function, changes in transcription are likely to reflect changes in biochemical processes. Thus, identifying transcriptional changes provides novel insight into the cellular response to ischaemia reperfusion and the pathways elicited for the development of delayed preconditioning.

cDNA.RDA identified six genes and three novel DNA sequences (Table 1) that were up-regulated in the myocardium in vivo during ischaemic PC. The novel DNA sequences showed no significant homology to previously described genes and at present we cannot infer any function for these genes in preconditioning. A detailed analysis of the function of the six known genes however provides clues to possible mechanisms that contribute to the development of preconditioning.

Expression of Trip1, Ppp2r1a, and Ncbp1 was consistently elevated between 2-6 $\mathrm{h}$ after PC. The time course of gene expression does not resemble the immediate early gene response seen for many transcription factors (eg. c-fos) and it is likely that these genes are part of the subsequent wave of gene expression resulting from the immediate early response. The timing of their expression also occurs after the first window of protection and thus they are unlikely to play a role in cardio-protection at early times. However, the relatively late expression of these genes raises the possibility that they contribute to the development of delayed adaptation. The role of these genes in the development of late adaptation to stress is further supported by the observation that they are induced in a similar fashion following heat induced preconditioning, thus suggesting they represent conserved, fundamental pathways in the adaptation to stress.

\section{Trip1}

Trip1 was first identified as a protein which interacts with the TGF $\beta$ type II receptor (Chen et al., 1995). It was shown to be phosphorylated by the receptor and complexed with the ligand-bound heteromeric complex (Chen et al., 1995). TRIP1 appears to selectively modulate the response of the TGF $\beta$ receptor, but is not an effector of the TGF $\beta$ response. TGF $\beta$ is a cytokine with pleiotropic and often opposing functions (Massague et al., 1992) involved in the regulation of cell proliferation, expression of extracellular matrix proteins, angiogenesis and wound healing. Previous reports indicated that ischaemia/ reperfusion, hyperthermia and hypoxia induce expression of TGF $\beta$ (Falanga et al., 1991) and that exogenous TGF $\beta$ can protect against ischaemia-reperfusion injury in several species (Lefer et al., 1990; Baxter et al., 2001), Roberts et al., 1993). Thus, induction of Trip1 during PC may protect the myocardium following acute ischaemia through modulation of the TGF $\beta$ signal transduction pathway.

TRIP1 is identical in sequence to the protein translation initiation factor elF3p36. TRIP1 is likely to 
have multiple functions as other protein initiation factors are not co-immunoprecipitated with TGF $\beta$ receptors. Induction of Trip1 may also have effects on the protein translation machinery. Both ischaemia and heat shock inhibit overall levels of protein synthesis. A recent report (Huang et al., 2004) demonstrated over-expression of Trip1 in a variety of hepatic carcinoma cell lines.

\section{Ppp2r1a and phosphatase 2 (PP2)}

Ppp2r1a codes for the $\alpha$ isoform of the A subunit of PP2 (formerly known as protein phosphatase 2A; Janssens and Goris, 2001). PP2 is composed of three subunits: the regulatory $A$ and $B$ subunits and the catalytic, $C$ subunit. The catalytic activity of the $C$ subunit does not require the $A$ and $B$ subunits, but when bound as a dimer with the A subunit (PP2D) or as a trimer with both $A$ and $B$ subunits, the catalytic functions and subcellular location are regulated by its binding partners. The A subunit (formerly PR65) exists as two isoforms, $\alpha$ and $\beta$ and acts as scaffolding for binding of the $B$ and $C$ subunits. Evidence suggests, however, that the $A$ subunit can act independently binding other cellular proteins.

In addition to the $B$ and $C$ subunits, at least four other cellular proteins are known to bind the free $A$ subunit (Janssens and Goris, 2001). These include C-terminal Jun N-terminal kinase (JNK; Shanley et al., 2001), RAF-1 (Abraham et al., 2000), heat shock factor 2 (HSF2; Hong and Sarge, 1999), and caspase 3 (Santoro et al., 1998). JNK is a stress activated protein kinase which phosphorylates JUN, affecting transcription through AP1, and its activation can lead to the induction of apoptosis. RAF1 is part of the ras/raf/erk signal transduction pathway and ERK expression has a protective anti-apoptotic role in the response to oxidative stress. Thus, interaction with the PP2A subunit provides cross-talk between the PP2 signal transduction pathways and known stress response pathways. Little is known about the subtle functional differences between the $\alpha$ and $\beta$ isoforms and how increased expression of the $\alpha$ isoform may modulate the role of the A subunit.

The PP2 holoenzyme is a serine/threonine phosphatase, which regulates phosphorylation of a variety of cell signalling proteins with a well established role in cell survival and apoptosis. Loss of PP2 activity in Drosophila leads to activation of caspases and may induce apoptosis (Silverstein et al., 2002). Similar results were found in mammalian cells (Strack et al., 2004). PP2 is also a well characterised regulator of the MAP kinase signalling pathways with both positive and negative effects depending upon cell type (Gallego and Virshup, 2005). PP2 is a positive regulator of RAF1 activation (Abraham et al., 2000) and can dephosphorylate both MEK and ERK in vitro (Haccard et al., 1990; Alessi et al., 1995).

In view of Trip1 regulation by PC stimuli, it is interesting to note that PP2 plays a role in TGF $\beta$ inhibition of p70S6kinase. Petritsch et al., (2000) showed that TGF $\beta$ inhibits p70S6kinase by establishing or stabilising complex formation between PP2 and p70s6kinase, where PP2 leads to dephosphorylation and inactivation of its activity.

HSF2 is a constituitively expressed member of the heat shock factor transcription family. HSF2 binds the A subunit at a position over-lapping with the binding site of the catalytic subunit and therefore competes with the $C$ subunit for $A$ subunit binding. In Jurkat cells, HSF2 binding to the A subunit leads to an increase in PP2 enzyme activity (Hong and Sarge, 1999). Thus PC may elevate levels of the A subunit modulating PP2 activity and possibly sequestering HSF2 and regulating downstream events.

Caspase 3 is a key enzyme in the apoptosis cascade. This protease is able to distinguish between the $A$ subunit $\alpha$ and $\beta$ isoforms, specifically cleaving the $\alpha$ isoform (PPP2r1a), indicating a unique functional role for the $\alpha$ isoform (Santoro et al., 1998). Several lines of evidence implicate caspase 3 in ischaemia/reperfusion induced apoptosis (Piot et al., 1999; Condorelli et al., 2001).

Recent reports indicated that PP2 may be a target of hypoxia and play a fundamental role in cardiac function. Truttmann et al. (2004) demonstrated that hypoxia decreased catalytic activity and protein levels of the PP2 catalytic subunit in cerebral cortex of newborn piglets. Gergs et al., (2004) generated transgenic mice with tissue specific over-expression of the catalytic subunit alpha (PP2acaAlpha) in the heart. Over-expression led to tissue necrosis and fibrosis and altered phosphorylation of a number of PP2 target proteins. These mice developed cardiac hypertrophy and reduced contractility of the heart. The authors concluded that PP2 had a fundamental role in cardiac function. These data support our work, which suggests that PP2 through up-regulation of its regulatory subunit, may play a role in cardioprotection developed during PC.

\section{Ncbp1}

Ncbp1 encodes the $80 \mathrm{kDa}$ CB80 protein, which together with $\mathrm{CB} 20$ forms the RNA cap binding protein $(C B C)$. CBC plays a role in RNA splicing and transport and its activity is induced by stress activated signalling pathways (Wilson et al., 1999).

The expression of the above genes in PC is a novel finding and complements other gene studies (Simkhovich et al., 2002; Zubakov et al., 2003). Zubakov et al., (2003) also used cDNA.RDA to investigate gene 
expression in PC myocardium. Their study used canine myocardium and differed from our work in that the subtractions were performed using tissue reperfused for $8 \mathrm{hr}$ and $16 \mathrm{~h}$ and the genes they isolated were those differentially expressed between $8 \mathrm{~h}$ and $16 \mathrm{~h}$ in PC myocardium of reperfusion. In contrast, we performed subtractions at three different time points using sham treated and PC tissue and identified changes in gene expression between PC and untreated controls at the same time point.

Simkhovich et al., (2002) examined gene expression in preconditioned rabbit heart by hybridising radiolabelled cDNAs from PC and sham treated animals on separate filter membranes arrayed with human cDNAs. Inevitably, hybridisation experiments using material from different species reduces the sensitivity of the technique, and the genes identified will be limited to the subset of genes explored and the technology used. Results are highly dependent on the platform used for gene analysis with filter membranes, cDNA microarrays and Genechips each identifying different subsets of genes, reflecting the different hybridisation conditions employed.

Ischaemic preconditioning protects by activating prosurvival kinases at reperfusion (Hausenloy et al., 2005). The PI3K-Akt and MEK-1/2-ERK-1/2 kinases, which they have termed the reperfusion injury salvage kinase pathway (RISK), are phosphorylated at reperfusion in response to an ischaemic stimulus (Hausenloy and Yellon, 2004). Phoshorylation of Akt and ERK 1-2 and their downstream target, p70 S6Kinase, in rat, is required for ischaemia induced $\mathrm{PC}$ protection. We therefore envisage that up-regulation of Ppp2r1a 2-6 hours after PC treatment acts to modify the MAP kinase signalling pathway, either by directly intereacting with RAF1 or by altering the activity of the PP2 holoenzyme in such a way as to influence its ability to dephosphorylate its targets: RAF, MEK, ERK and p70S6kinase. Similarly, Tripl, as well as its potential role in modifying TGF $\beta$ signalling pathways, may also influence the reperfusion injury salvage kinase cascade through its effects on PP2 and p70S6kinase.

\section{Acknowledgement}

This work was funded in part through grants from the British Heart Foundation, Brighton Heart Support Trust, The RM Phillips Charitable Foundation and Glaxo Smith Kline PLC. Thanks to Dr Kevin Lawrence, Dept. Molecular Medicine, ICH-UCL for comments on the manuscript.

\section{References}

Abraham D, Podar K, Pacher M, Kubicek M, Welzel N,
Hemmings BA, Dilworth SM, Mischak H, Kolch W, Baccarini M. Raf-1-associated protein phosphatase $2 \mathrm{~A}$ as a positive regulator of kinase activation J Biol Chem 2000; 275:22300-4

Alessi DR, Gomez N, Moorhead G, Lewis T, Keyse SM, Cohen P. Inactivation of p42 MAP kinase by protein phosphatase $2 \mathrm{~A}$ and a protein tyrosine phosphatase, but not CL100, in various cell lines Curr Biol 1995; 5:283-95

Barrientos A, Moraes CT. Titrating the effects of mitochondrial complex I impairment in the cell physiology J Biol Chem 1999; 274:16188-97

Baxter GF, Goma FM, Yellon DM. Characterisation of the infarct-limiting effect of delayed preconditioning: timecourse and dose-dependency studies in rabbit myocardium Basic Res Cardiol 1997; 92:159-67

Baxter GF, Mocanu MM, et al. Cardioprotective effects of transforming growth factor-b1 during early reoxygenation or reperfusion are mediated by p42/p44 MAPK. J Cardiovasc Pharmacol 2001;38:930-9

Baxter GF, Yellon DM. Delayed preconditioning against lethal ischaemic injury In Delayed preconditioning and adaptive cardioprotection, (Baxter GF, Yellon DM, eds), from Developments in Cardiovascular Medicine: Vol 207, 1998;1-23 Springer, New York, NY

Brand T, Sharma HS, Fleischmann KE, Duncker DJ, McFalls EO, Verdouw PD, Schaper W. Proto-oncogene expression in porcine myocardium subjected to ischemia and reperfusion Circ Res 1992;71:1351-60

Carper DA, Sun JK, Iwata T, Zigler JS, Jr, Ibaraki N, Lin LR, Reddy V. Oxidative stress induces differential gene expression in a human lens epithelial cell line Invest Ophthalmol Vis Sci 1999;40:400-6

Chen RH, Miettinen PJ, Maruoka EM, Choy L, Derynck RA. WD-domain protein that is associated with and phosphorylated by the type II TGF-beta receptor Nature 1995;377: 548-52

Choy L, Derynck R. The type II transforming growth factor (TGF)-beta receptor-interacting protein TRIP-1 acts as a modulator of the TGF-beta response J Biol Chem 1998;273: 31455-62

Condorelli G, Roncarati R, Ross J, Jr, Pisani A, Stassi G, Todaro M, Trocha S, Drusco A, Gu Y, Russo MA, Frati G, Jones SP, Lefer DJ, Napoli C, Croce CM. Heart-targeted overexpression of caspase3 in mice increases infarct size and depresses cardiac function Proc Natl Acad Sci USA 2001; 98:9977-82

Currie R, Plumier J-C. The heat shock response and tissue protection In Delayed preconditioning and adaptive cardioprotection, (Baxter GF, Yellon DM, eds), from Developments in Cardiovascular Medicine: Vol 207, 1998,135-153 Springer, New York, NY

Falanga V, Qian SW, Danielpour D, Katz MH, Roberts AB, Sporn MB. Hypoxia upregulates the synthesis of TGF-beta 1 by human dermal fibroblasts J Invest Dermatol 1991;97:634-7

Gallego M, Virshup DM. Protein serine/threonine phosphatases: life, death, and sleeping Curr Opin Cell Biol 2005;17:197-202 
Gergs U, Boknik P, Buchwalow I, Fabritz L, Matus M, Justus I, Hanske G, Schmitz W, Neumann J. Overexpression of the catalytic subunit of protein phosphatase $2 \mathrm{~A}$ impairs cardiac function J Biol Chem 2004;279:40827-34

Haccard O, Jessus C, Cayla X, Goris J, Merlevede W, Ozon $\mathrm{R}$. In vivo activation of a microtubule-associated protein kinase during meiotic maturation of the Xenopus oocyte. Eur J Biochem 1990;192:633-42

Hausenloy DJ, Yellon DM. New directions for protecting the heart against ischaemia-reperfusion injury: targeting the Reperfusion Injury Salvage Kinase (RISK)-pathway. Cardiovasc Res 2004; 61:448-60

Hausenloy DJ, Tsang A, Mocanu MM, Yellon DM. Ischemic preconditioning protects by activating prosurvival kinases at reperfusion. Am J Physiol Heart Circ Physiol 2005;288: H971-6

Hong $\mathrm{Y}$, Sarge KD. Regulation of protein phosphatase $2 \mathrm{~A}$ activity by heat shock transcription factor 2. J Biol Chem 1999;274:12967-70

Huang JS, Chao CC, Su TL, Yeh SH, Chen DS, Chen CT, Chen PJ, Jou YS. Diverse cellular transformation capability of overexpressed genes in human hepatocellular carcinoma. Biochem Biophys Res Commun 2004;315:950-8

Hubank M, Schatz DG. Identifying differences in mRNA expression by representational difference analysis of cDNA. Nucleic Acids Res 1994;22:5640-8

Hubank M, Schatz DG. cDNA representational difference analysis: a sensitive and flexible method for identification of differentially expressed genes. Methods Enzymol 1999;303: 325-49

Janssens V, Goris J. Protein phosphatase 2A: a highly regulated family of serine/threonine phosphatases implicated in cell growth and signalling. Biochem J 2001;353:417-39

Kuzuya T, Hoshida S, Yamashita N, Fuji H, Oe H, Hori M, Kamada T, Tada M. Delayed effects of sublethal ischemia on the acquisition of tolerance to ischemia. Circ Res 1993; 72:1293-9

Lefer AM, Tsao P, Aoki N, Palladino MA, Jr. Mediation of cardioprotection by transforming growth factor-beta. Science 1990; 249:61-4

Lisitsyn N, Wigler M. Cloning the differences between two complex genomes. Science 1993;259:946-51

Marber MS, Latchman DS, Walker JM, Yellon DM. Cardiac stress protein elevation 24 hours after brief ischemia or heat stress is associated with resistance to myocardial infarction. Circulation 1993;88:1264-72

Massague J, Cheifetz S, Laiho M, Ralph DA, Weis FM, Zentella A. Transforming growth factor-beta. Cancer Surv 1992; 12:81-103

Matsushita K, Umezawa A, Iwanaga S, Oda T, Okita $H$, Kimura K, Shimada M, Tanaka M, Sano M, Ogawa S, Hata J. The EAT/mcl-1 gene, an inhibitor of apoptosis, is up-regulated in the early stage of acute myocardial infarction. Biochim Biophys Acta 1999; 1472:471-8

May BK, Bhasker CR, Bawden MJ, Cox TC. Molecular regulation of 5-aminolevulinate synthase. Diseases related to heme biosynthesis. Mol Biol Med 1990; 7:405-21

Mayne LV. Changes in cardiac gene expression after ischaemia and reperfusion In Delayed preconditioning and adaptive cardioprotection, (Baxter, G. F. and Yellon, D. M. eds), from Developments in Cardiovascular Medicine: 1998;207:111-33 Springer, New York, NY

Murry CE, Jennings RB, Reimer K. A. Preconditioning with ischemia: a delay of lethal cell injury in ischemic myocardium. Circulation 1986; 74:1124-36

Onody A, Zvara A, Hackler L, Jr, Vigh L, Ferdinandy P, Puskas LG. Effect of classic preconditioning on the gene expression pattern of rat hearts: a DNA microarray study. FEBS Lett 2003; 536:35-40

Petritsch C, Beug H, Balmain A, Oft M. TGF-beta inhibits p70 S6 kinase via protein phosphatase $2 A$ to induce $G(1)$ arrest. Genes Dev 2000;14:3093-101

Piot CA, Martini JF, Bui SK, Wolfe CL. Ischemic preconditioning attenuates ischemia/reperfusion-induced activation of caspases and subsequent cleavage of poly(ADP-ribose) polymerase in rat hearts in vivo. Cardiovasc Res 1999; 44:536-42

Roberts AB, Sporn MB, Lefer AM. Cardioprotective actions of transforming growth-factor-beta trends in cardiovascular. Medicine 1993;3:77-81

Runswick MJ, Fearnley IM, Skehel JM, Walker JE. Presence of an acyl carrier protein in NADH:ubiquinone oxidoreductase from bovine heart mitochondria. FEBS Lett 1991;286:121-4

Santoro MF, Annand RR, Robertson MM, Peng YW, Brady MJ, Mankovich JA, Hackett MC, Ghayur T, Walter G, Wong WW, Giegel DA. Regulation of protein phosphatase 2A activity by caspase-3 during apoptosis. J Biol Chem 1998; 273:13119-28

Shanley TP, Vasi N, Denenberg A, Wong HR. The serine/ threonine phosphatase, PP2A: endogenous regulator of inflammatory cell signaling. J Immunol 2001;166:966-72

Silverstein AM, Barrow CA, Davis AJ, Mumby MC. Actions of PP2A on the MAP kinase pathway and apoptosis are mediated by distinct regulatory subunits. Proc Natl Acad Sci USA 2002; 99:4221-6

Simkhovich BZ, Abdishoo S, Poizat C, Hale SL, Kedes LH, Kloner RA. Gene activity changes in ischemically preconditioned rabbit heart gene: discovery array study. Heart Dis 2002;4:63-9

Simkhovich BZ, Marjoram P, Poizat C, Kedes L, Kloner RA. Brief episode of ischemia activates protective genetic proin rat heart: a gene chip study. Cardiovasc Res 2003;59:450-9

Strack S, Cribbs JT, Gomez L. Critical role for protein phosphatase $2 \mathrm{~A}$ heterotrimers in mammalian cell survival. J Biol Chem 2004;279:47732-9

Truttmann AC, Ashraf Q, Mishra OP, Delivoria-Papadopoulos $M$. Effect of hypoxia on protein phosphatase $2 A$ activity, subcellular distribution and expression in cerebral cortex of newborn piglets. Neuroscience 2004;127:355-63

Wilson KF, Fortes P, Singh US, Ohno M, Mattaj IW, Cerione 
RA. The nuclear cap-binding complex is a novel target of growth factor receptor-coupled signal transduction. J Biol Chem 1999;274:4166-73

Zubakov D, Hoheisel JD, Kluxen FW, Brandle M, Ehring T,
Hentsch B, Frohme M. Late ischemic preconditioning of the myocardium alters the expression of genes involved in inflammatory response. FEBS Lett 2003;547:51-5 